УДК 004.42

DOI https://doi.org/10.32838/2663-5941/2021.4/14

\title{
Коцун B.I.
}

ПВНЗ «Европейський університет»

\section{НАВЧАЛЬНА ПРОГРАМА ДЛЯ ВИВЧЕННЯ ФІЗИКИ «МЕХАНІКА. ОСНОВИ КІНЕМАТИКИ»}

У статті розглядається реалізачія навчальної програми для вивчення фізики «Механіка. Основи кінематики». Мета створення програми полягає в допомозі учням і студентам у вивченні фізики. Створено АРІ-додаток для узгодження локальної програми з базою даних на віддаленому сервері. АРIдодаток розроблено мовою програмування JavaScript. Node.js - платформа для виконання високопродуктивних мережевих застосунків, написаних мовою JavaScript. Протоколом передачі даних обрано REST. Як файли для передачі інформачії обрано файли у форматі JSON. Для створеного API-додатка була використана бібліотека Sequеlize, яка здійснює зіставлення таблиць у базі даних і співвідномень між ними й класами. Фреймворк Express.js був обраний для створення API-додатку.

Протягом усієї історії людства основним рушісм його розвитку було пізнання світу й себе в иьому світі. 3 давніх-давен людина прагнула дослідити навколишній світ, намагаючись пояснити ті явища, які бачила. 3 плином часу людство почало не лише споглядати за природою, а й намагалось застосовувати ї̈ закони, знаходячи закономірності певних явищ, розкриваючи їх причину. Так з'являлись перші винаходи: різноманітні механізми, пристрої тощо. За допомогою иих засобів людина змогла полегшити свою праџю, вдосконалити свою майстерність. Навчивщись прогнозувати фізичні явища й керувати ними, людина стала «велетнем»: вона створила двигуни, у мільйони разів потужніші за людські руки, комп'ютери, які розширили можливості науки, техніки й мистецтва.

Проаналізовано наявні онлайн-ресурси й додатки для вивчення різних наук і показано їх основні переваги й недоліки. Наведено основні фактори необхідності реалізаиї програмного засобу для вивчення фізики. Обтрунтовано дочільність використання обраних технологій для розробки навчальної програми.

У роботі реалізована можливість перегляду навчальних матеріалів, після вивчення яких користувач зможе провести експерименти й побачити їхні результати у вигляді зображень, графіків і таблиць. Також користувачі можуть зареєструватися та авторизуватися в програмі, щзо дозволить зберігати результати свого навчального прогресу.

Показано, щз завданням створеної навчальної програми є допомога у вивченні теоретичних матеріалів і закріплення знань за допомогою інтерактивного експерименту.

Ключові слова: фізика, програмування, навчальна програма, клієнт-сервер, C\#, Windows-додаток.

Постановка проблеми. Протягом усієї історії людства основним рушієм його розвитку було пізнання світу й себе в цьому світі. 3 давніхдавен людина прагнула дослідити навколишній світ, намагаючись пояснити ті явища, які бачила. 3 плином часу людство почало не лише споглядати за природою, а й намагалось застосовувати іiї закони, знаходячи закономірності певних явищ, розкриваючи їх причину. Навчившись прогнозувати фізичні явища й керувати ними, людина стала «велетнем»: вона створила двигуни, у мільйони разів потужніші за людські руки, комп'ютери, які розширили можливості науки, техніки й мистецтва, об'єднала всіх жителів Землі надійними системами зв'язку.

Відбулися глибокі, якісні зміни в багатьох галузях науки й техніки, пов'язані з важливими відкриттями в галузі фундаментальної фізики. Відкриття радіоактивності, електромагнітних хвиль, ультразвуку, реактивного руху тощо сприяли тому, що людина, застосовуючи ці знання, просунула розвиток техніки далеко вперед. Наука стала безпосередньою продуктивною силою. Однак справа не лише в «практичній» цінності фізики: знання фізики необхідне кожному 3 нас, щоб задовольнити природну цікавість у розумінні навколишнього світу.

Саме тому розроблення програмного засобу для вивчення фізики стало б засобом покращення розуміння або вивчення фізичних явищ, як для прикладу кінематичного прямолінійного руху.

Аналіз останніх досліджень i публікацій. У світі існує величезна кількість онлайн-ресурсів та додатків для вивчення різних наук. Але мені вдалося з'ясувати, що для вивчення матеріалів 3 фізики існує не так і багато програмних засобів.

Одним із ресурсів, що дозволяє вивчити основи фізики, $є$ Get a Class - це збірка онлайн-курсів із 
математики й фізики. Цей онлайн-ресурс має багато переваг: він $\epsilon$ безкоштовним, на ньому міститься багато навчальних матеріалів 3 фізики, доступні відео 3 поясненнями та експериментами [1]. Ще однією перевагою є наявність тестів на перевірку знань. GetAClass можна використовувати як інструмент для підготовки до зовнішнього незалежного оцінювання / державної підсумкової атестації.

До недоліків цих онлайн-курсів можна віднести відсутність інтерактивних вправ та ігор для вивчення фізики, доступність матеріалу лиш на російській мові, поверхові вивчення тем з фізики. Попри ці недоліки, Get a Class чудовий безкоштовний онлайн-ресурс для вивчення фізики.

Нижче наведено інші відомі сервіси, які використовуються для вивчення фізики.

Сайт the Physics Classroom iснує ще з 1996 року [2]. Протягом років цей сайт розвивався та збільшувався та став великим онлайн-ресурсом, що надає студентам, викладачам та іншій аудиторії, готові матеріали $з$ фізики, що використовують просту та зрозумілу мову навчання.

До переваг цього ресурсу можна віднести величезну кількість навчальних матеріалів, безкоштовність цих матеріалів та інтерактивні пояснення та експерименти які можна проводити.

3 недоліків онлайн-ресурсу можна виокремити застарілий, не сучасний дизайн, доступність матеріалів лише англійською мовою.

Вебплатформа для навчання eduMedia мабуть поєднує у собі переваги попередньо згаданих онлайн-ресурсів [3]. На ній розміщена велика кількість тем для вивчення фізики, які доступні багатьма мовами, зокрема російською та англійською. Більшість матеріалу з фізики мають інтерактивні вправи, що дозволяє ефективніше вивчати матеріал. Платформа має сучасний зрозумілий дизайн. На мою думку, eduMedia має лише один недолік - ціну. Підписка на користування вебплатформою коштує недешево.

Brilliant.org - сайт і спільнота, що надає курси й задачі з математики, фізики, числових фінансів та інформатики [4]. Brilliant має на меті відкривати й розвивати математичні й наукові навички студентів, професіоналів та аматорів зі всього світу.

Brilliant має дуже багато переваг. Він має сучасний зрозумілий дизайн і багато тем і матеріалів для вивчення. Окрім вебсайту, Brilliant має мобільний додаток, який $є$ дуже зручним і зрозумілим. Попри ряд переваг, на мою думку, Brilliant має лише два недоліки: це відсутність української мови й ціна. У безкоштовній версії додатку доступна невелика кількість навчального матеріалу.
Мобільний додаток 4Physics - це унікальний у своєму роді додаток, що дозволяє проводити фізичні дослідження, використовуючи датчики мобільного телефону [5].

Цей додаток інтегрує потужність чотирьох датчиків у понад 25 суворих лабораторних досліджень, які дозволяють студентам вчитися за допомогою експериментів. Інтерактивність і можливість проведення досліджень та $є$ основною перевагою 4Physics. Він також містить основні навчальні матеріали 3 фізики, але їхня кількість невелика. Як і в більшості вищенаведених додатків, недоліками 4Physics $€$ відсутність української мови й ціна.

Загалом, усі досліджені мною програмні засоби для вивчення фізики можна поділити на дві категорії: безкоштовні й платні. У кожної категорії є ряд своїх недоліків. Наприклад, серед недоліків безкоштовних засобів для вивчення фізики $\epsilon$ незрозумілий дизайн і відсутність інтерактивних вправ. Платні ресурси для вивчення фізики мають високу ціну й в основному недоступні українською мовою.

Оскільки кожен із цих програмних засобів має свої недоліки, розробка аналогу актуальна, якщо врахувати недоліки конкурентів і виправити їх.

Постановка завдання. Метою роботи є розробка навчальної програми, який допоможе учням і студентам у вивченні фізики, а саме розділу «Механіка. Основи кінематики».

Виклад основного матеріалу дослідження. Для створення будь-якого програмного забезпечення правильно буде спочатку проаналізувати наявні методи й рішення, а також схоже програмне забезпечення. Це дозволить переглянути, які методи використовують розробники для створення програмного забезпечення. Оскільки варіантів реалізації програмного засобу є досить багато, це означає, що й проєкт може бути написано абсолютно на різних мовах програмування.

Для реалізації проєкту мною було обрано об'єктно-орієнтовану мову програмування С\# [6]. Оскільки програмне забезпечення було призначено виключно на операційну систему Windows, то C\# $\epsilon$ найкращим варіантом мови програмування для реалізації проєкту [7]. Саме з використанням цієї технології було створено програмний продукт.

Додаток розроблено, використовуючи клієнтсерверну архітектуру, де в ролі сервера виступає REST API [8] написаний на Node.js мовою програмування JS із підключенням бібліотек Express i Sequelize [9], а на стороні клієнту - Windowsдодаток, створений мовою програмування С\#. 
Оскільки серверна частина додатку працює як REST API, то було визначено, що дані мережею будуть передаватися у форматі JSON [10].

Для більш наглядного представлення компонентів, їх фізичного знаходження та варіантів комунікації між компонентами було побудовано діаграму розгортання (рис. 1).

Одним із найскладніших в відповідальних етапів в процесі проєктування було визначити й розробити структуру бази даних, оскільки від цього значною мірою залежить успіх майбутнього програмного продукту.

Тому було спроєктовано таку структуру бази даних із таблиць:

- "Users" - для зберігання персональних даних користувачів;

- "User_Progress" - для зберігання прогресу навчання користувачів;

- "Materials" - для зберігання навчальних матеріалів;

- "Themes" - буде містити навчальні матеріали згідно з обраними темами;

- "Resources" - для зберігання дрібних частинок матеріалу у формі відео, текстів, формул, експериментів.
Кожна таблиця має свою специфічну структуру даних, яка дає змогу зберегти інформацію в тому вигляді, в якому вона потрібна розробнику для виконання поставлених завдань. У базі даних використались різні зв'язки, які надали змогу структурно зв'язати дані між собою.

Оскільки це навчальна програма 3 фізики, яку і так не легко розуміти, то інтерфейс користувача повинен бути максимально простим і зрозумілим. Через те, що програма буде реалізована для ОС Windows, ii дизайн буде схожим до Windows і не буде вирізнятися чимось особливим.

Для створення користувацького інтерфейсу використовується бібліотека MaterialSkin [11], в якій є багато стандартних компонентів інтерфейсу. Нижче на рис. 2 наведено форму й меню додатку, створені за допомогою бібліотеки MaterialSkin.

Кожна вкладка має панель меню, яка розміщується в лівому кутку форми, що дає змогу швидко переключатися між вкладками додатку. Далі розглянемо створення інтерфейсу вкладки вибору тем. Для швидкого й зручного переміщення між темами було використано великі кнопки з назвами тем (рис. 3). У результаті натискання на кнопку «Теми» можна перейти до вкладки матеріалів обраної теми.
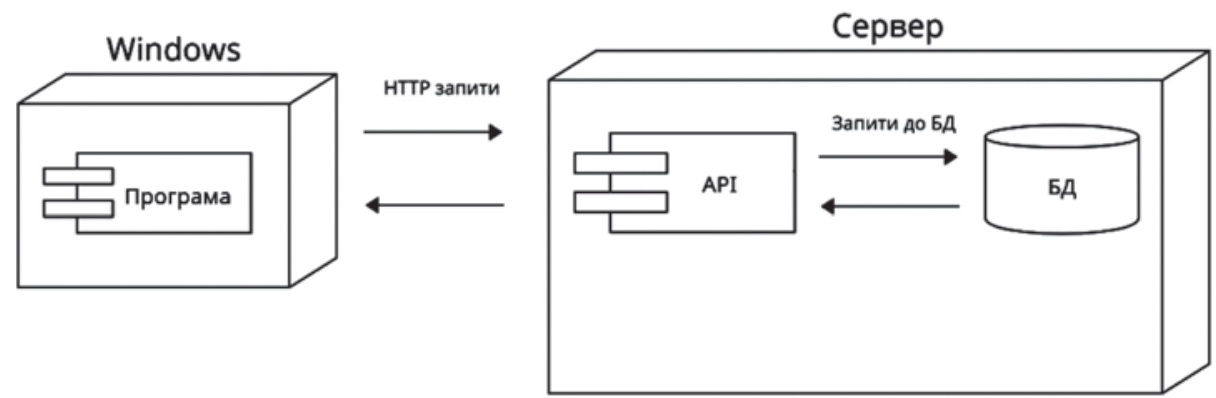

Рис. 1. Діаграма розгортання

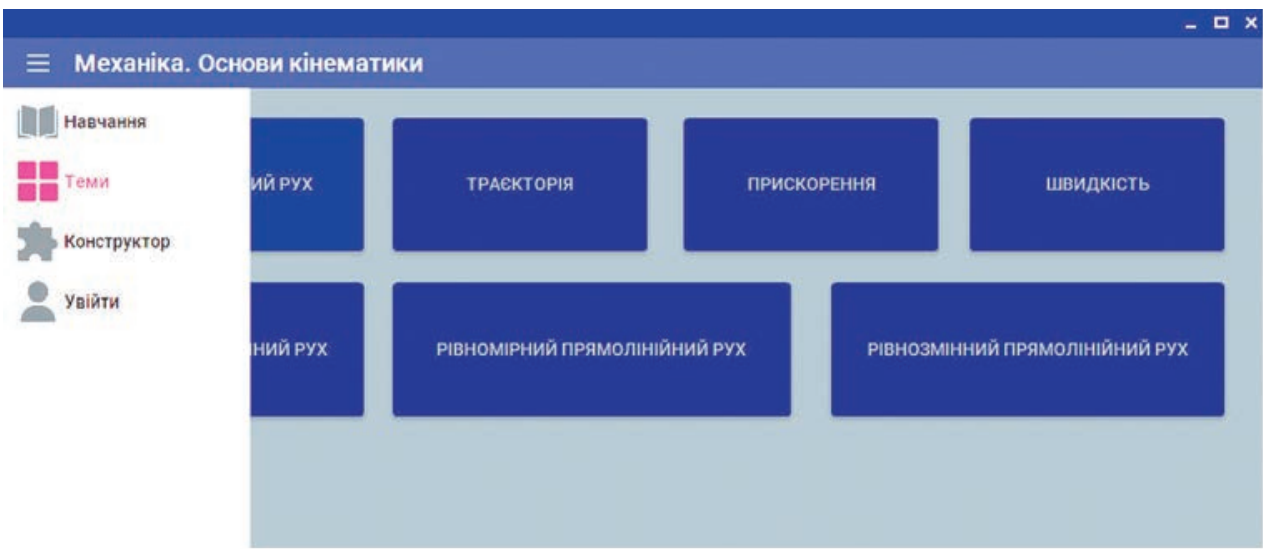

Рис. 2. Меню додатку 

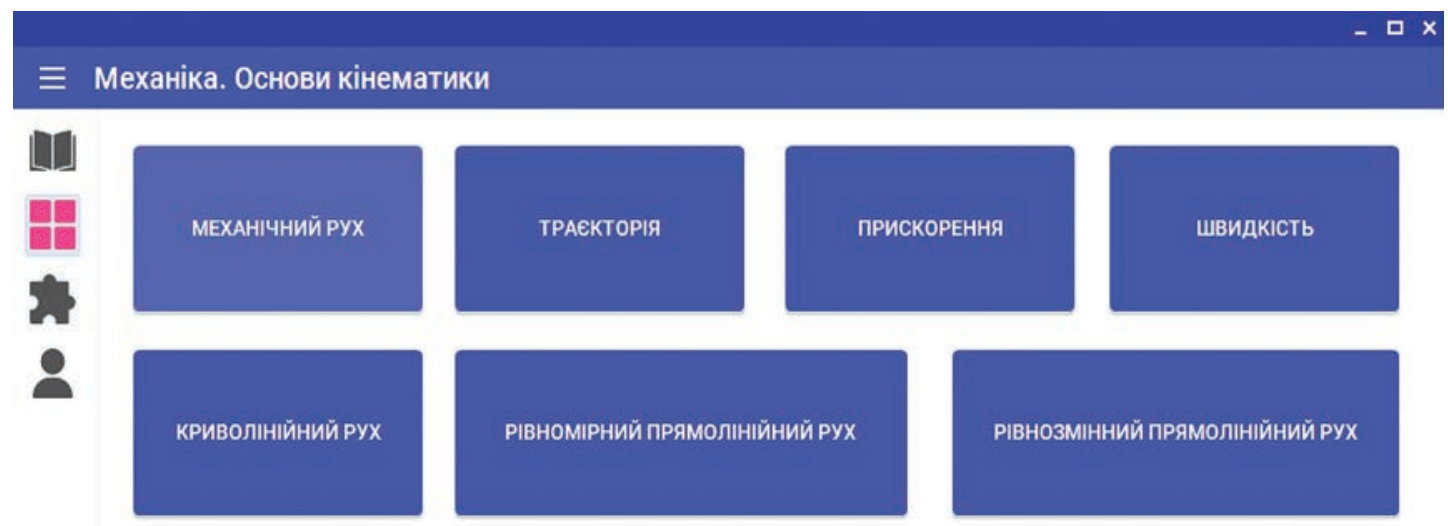

Рис. 3. Вкладка вибору тем

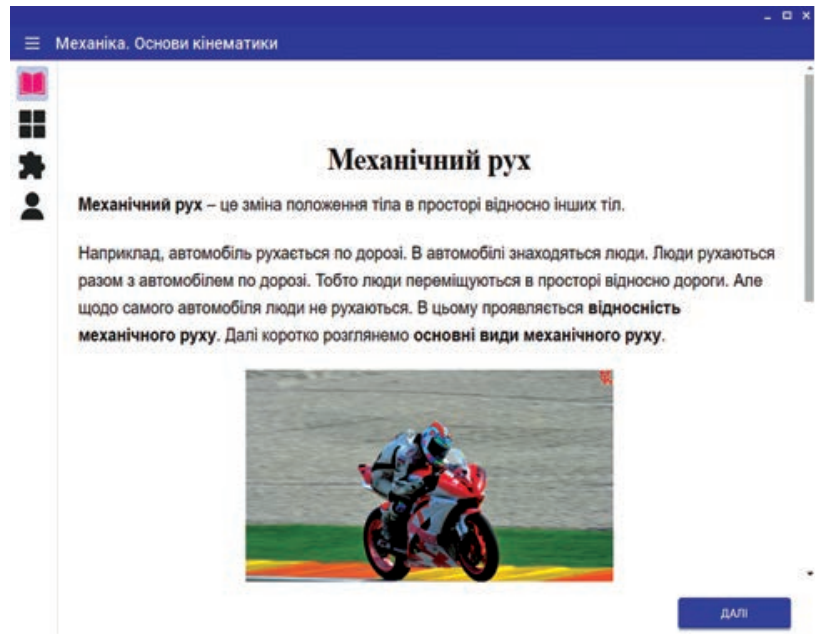

Рис. 4. Вкладка навчальних матеріалів

Також нижче можна побачити інтерфейс вкладки навчальних матеріалів із використанням технології WebView.

Також для зображення навчальних відео в цій вкладці використовується iFrame [12] 3 відео. Це дає змогу швидко та якісно відбивати відео для користувачів. Для прикладу наведемо інтерфейс зображення IFrame 3 навчальним відео на рис. 5.

Авторизації та аутентифікація в додатку виконується за допомогою сервісів Google, тобто увійти в систему чи зареєструватися в додатку можна лише за допомогою облікового запису Google. Для цього в додатку використовується технологія Google OAuth2. Вкладка авторизації зображена на рис. 6.

Після отримання токену доступу до облікового запису Google цей токен зберігається в додатку. Для

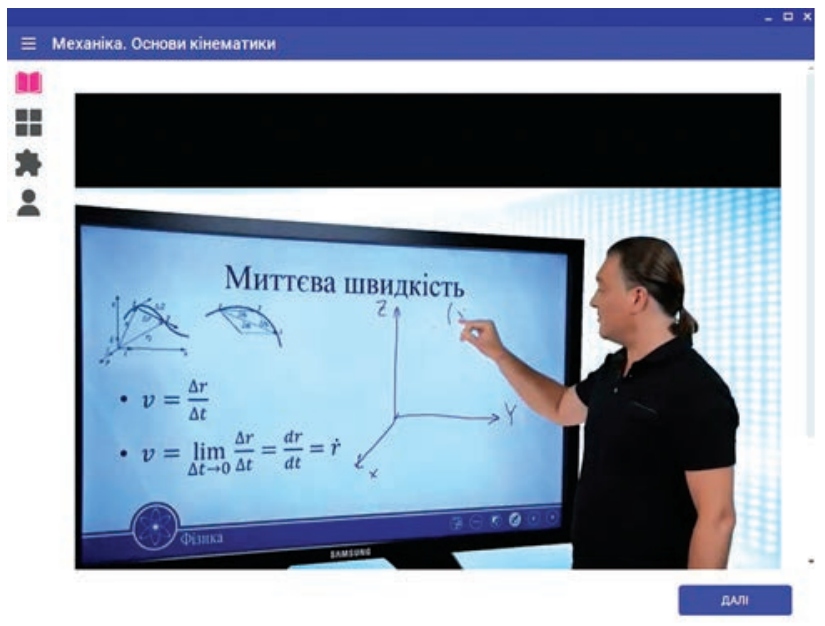

Рис. 5. Вкладка навчальних матеріалів із відео

кращого засвоєння навчальних матеріалів користувач може проводити інтерактивний експеримент, задаючи початкові характеристики об'єкту. Вигляд вкладки експериментів наведений на рис. 7.

Для прикладу, експеримент складається 3 об'єкта, який переміщається, координатної площини, де він переміщається, векторів (швидкості, прискорення, переміщення), графіків і таблиці, котрі описують рух об'єкта й зображують його числові характеристики. На рисунку нижче можна побачити траєкторію руху, числові характеристики об’єкта й результати експерименту.

Після розробки було проведено модульне й функціональне тестування додатку, яке допомогло виявити його недоліки й помилки. Після цього помилки було виправлено й додаток ще раз був наданий для тестування кільком реальним користувачам. 


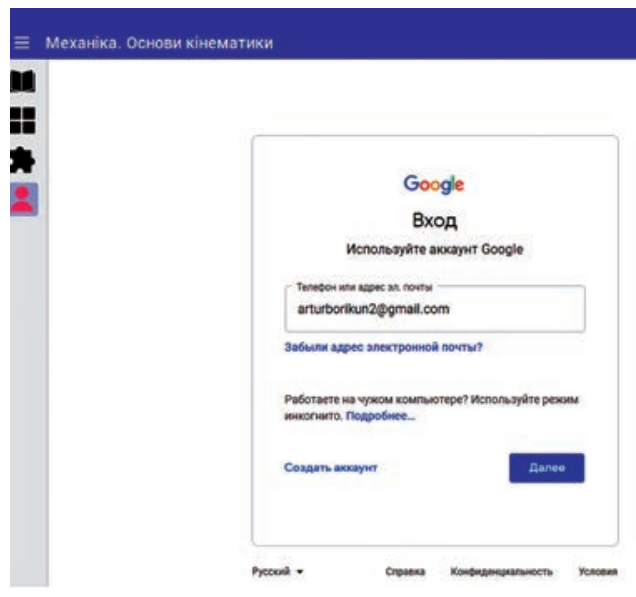

Рис. 6. Вкладка авторизації

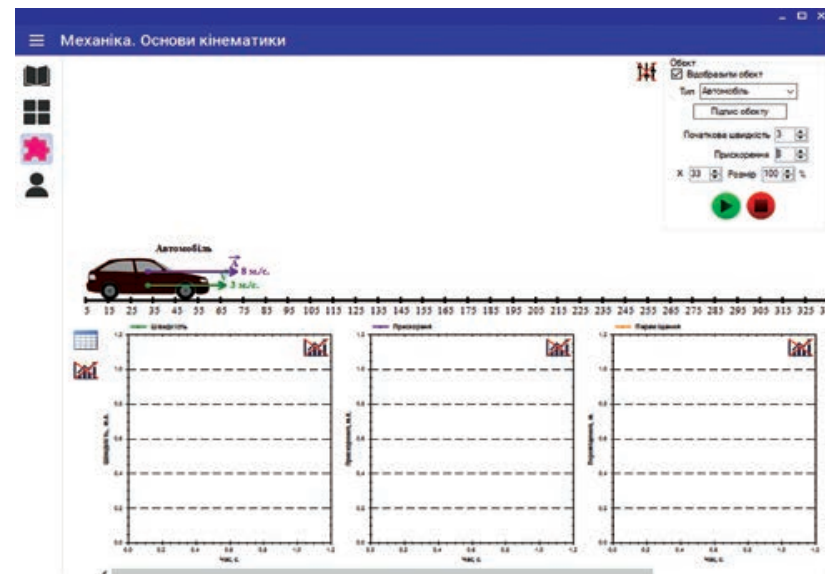

Рис. 7. Вкладка експериментів

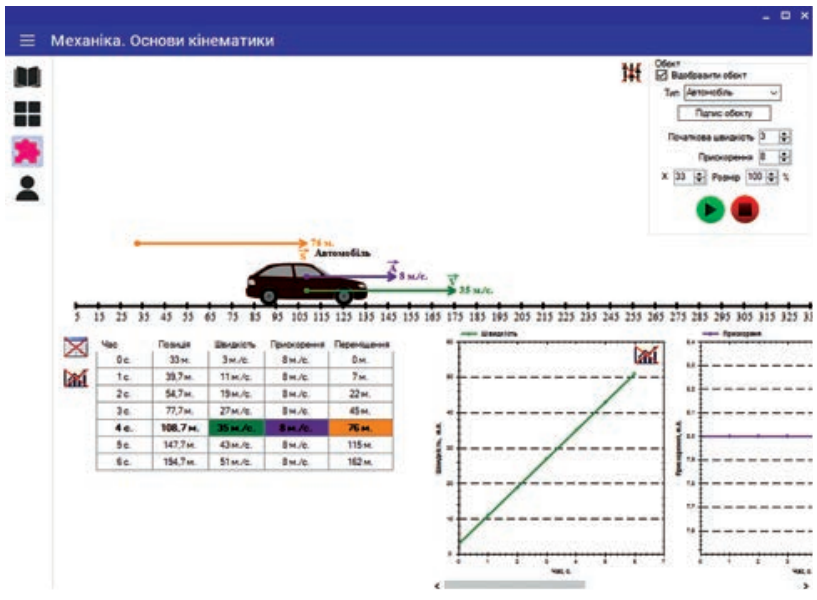

Рис. 8. Вкладка результатів експерименту

Висновки. У результаті проведеної роботи було створено навчальну програму, яка допомагає вивченню теоретичних основ окремих тем із фізики й засвоєнню набутих знань за допомогою інтерактивного експерименту. Програмний засіб є багатофункціональним, містить багато корисних функцій котрі допоможуть пришвидшити обрахунки і проведення експериментів, а повноцінне графічне зображення фізичних процесів допоможе користувачеві краще засвоїти навчальний матеріал.

\section{Список літератури:}

1. GetAClass. URL: https://www.getaclass.ru (дата звернення: 01.06.2021).

2. The Physics Classroom. URL: https://www.physicsclassroom.com (дата звернення: 01.06.2021).

3. EduMedia. URL: https://www.edumedia-sciences.com/en (дата звернення: 01.06.2021).

4. Brilliant. URL: https://brilliant.org (дата звернення: 01.06.2021).

5. Lab4Physics.URL:https://apps.apple.com/us/app/lab4physics/id104940508 (датазвернення:01.06.2021).

6. Скит Дж. С\#. Программирование для профессионалов / пер. В. Коваленко. Второе издание. Киев : Вильямс, 2011. 544 с.

7. Троелсен Э. Язык программирования С\#5.0 и платформа .NET 4.5. 6-е издание. Киев : Вильямс, 2013. 1312 c.

8. Cantelon M., Harter M., Holowaychuk T., Rajlich N. Node.js in Action. Manning Publications, 2013. 416 c.

9. Бібліотека Sequelize. URL: https://sequelize.org/master/manual (дата звернення: 02.06.2021).

10. Анотація JSON. Вікіпедія: вільна енииклопедія. URL: https://uk.wikipedia.org/wiki/JSON (дата звернення: 02.06.2021).

11. MaterialSkin. URL: https://github.com/IgnaceMaes/MaterialSkin (дата звернення: 02.06.2021).

12. Що таке iFrame? URL: https://www.hostinger.com.ua/rukovodstva/shto-takoje-iframe (дата звернення: 02.06.2021). 


\section{Kotsun V.I. CURRICULUM FOR THE STUDY OF PHYSICS “MECHANICS. FUNDAMENTALS OF KINEMATICS"}

The article takes into account the curriculum implementation for the possibility of studying the chapter of physics named "Mechanics. Fundamentals of kinematics". The program development goal is to help students in the learning of physics. Developed API-application is implemented for communications of the local program with basic data on a remote server. The API-application developed in the JavaScript programming language. The Node.js platform, used to run high-performance networking applications, is written in JavaScript. REST is selected as the data transfer protocol. A file in JSON format is generated as files for information transfer. To create a new API-application, the Sequelize library is used, which provides collaboration of tables in the database and the relationship between them and classes. The Express.js framework is used to create an additional API-program.

The world knowledge and human beings in this world was the main reason which permitted humanity to develop themself during all historical moments. From time immemorial, humanity has sought to explore the outworld, try to explain the surrounding phenomena. Over time, humanity started to use the laws of nature and not only observed them by finding the main principles of certain phenomena and discovering their causes. This phenomena investigation caused the development of various mechanisms, devices, etc. By means of using these tools, humanity was able to facilitate their work by improving their skills.

By learning to predict and control physical phenomena, humanity became a "giant", by creating engines that are millions of times more powerful than human hands, computers that expanded the opportunities of science, technology, and art.

In the article, for studying various sciences the existing online resources and applications are analyzed as well as their main advantages and disadvantages are shown. For the study of physics, the main reasons for the necessity of software implementation are shown. For curriculum development, the expediency of using the chosen technologies is substantiated.

In the developed application, the possibility of reviewing the educational materials is realized during the study process. Also users have the ability to provide the experiment and observe their results in images, graphical and tables formats. For sure, from a user perspective, the developed application can provide the ability to register, login and save the results of the user's learning progress.

The goals of the developed application are learning the theoretical materials and consolidating the knowledge through an interactive experiment.

Key words: physics, programming, curriculum, client-server, C\#, Windows `s application. 